Original Article

\title{
The Effects of VR-based Wii Fit Yoga on Physical Function in Middle-aged Female LBP Patients
}

\author{
SeOng-Sik Kim, PT, MSc1), Won-Kyu Min, PT, MSc1), Jung-HeE KIm, PT, MSc1), \\ Byoung-Hee Lee, PT, PhD ${ }^{1)^{*}}$ \\ 1) Graduate School of Physical Therapy, Sahmyook University: 815 Hwarang-ro, Nowon-gu, Seoul \\ 139-742, Republic of Korea
}

\begin{abstract}
Purpose] The purpose of this research was to determine the effects of a virtual reality-based yoga program on middle-aged female low back pain patients. [Subjects and Methods] Thirty middle-aged female patients who suffered from low back pain were assigned to either a physical therapy program or a virtual reality-based yoga program for a period of four weeks. Participants could check their posture and weight bearing on a monitor as they shifted their weight or changed their postures on a Wii balance board. There were a total of seven exercise programs. A 30-minute, three times per week, virtual reality-based Wii Fit yoga program or trunk stabilizing exercise was performed, respectively. [Results] Repeated-measures analysis of covariance revealed significant differences in between pre- and post-training VAS, algometer, Oswestry low-back pain disability index (ODI), Roland Morris disability questionnaire (RMDQ), and fear avoidance beliefs questionnaire (FBQ) scores. The VAS, algometer, ODI, RMDQ, and FBQ scores showed significant differences in groups. Regarding the effect of time-by-group interaction, there were significant differences in VAS, ODI, ODI, and FBQ scores. [Conclusion] In conclusion, for middle-aged female patients who have low back pain, a virtual reality-based yoga program was shown to have positive effects on physical improvements, and this program can be employed as a therapeutic medium for prevention and cure of low back pain.

Key words: Low back pain, Virtual reality, Yoga
\end{abstract}

(This article was submitted Sep. 4, 2013, and was accepted Nov. 4, 2013)

\section{INTRODUCTION}

Low back pain (LBP) is a symptom experienced by $80 \%$ of adults at least once in their life time. Nowadays, especially due to industrialization, the number of occurrences is increasing ${ }^{1)}$. Often, relief of light pain is achieved naturally within two months. If the pain persists for longer than three months, it develops as chronic pain ${ }^{2}$. In a previous study, the prevalence of LBP was higher among women than among men in all age groups $(n=92,936)$, with the highest values seen in the middle-aged woman group ${ }^{3)}$. Thus, therapeutic intervention and preventative activities for LBP are significantly important for middle-aged women. Among the many interventions for treatment of LBP, causes of LBP are diverse, and its patterns are also varied. Yoga and stretching are known to be effective for relief of LBP symptoms ${ }^{4-6)}$, and yoga and stretching are widely utilized as rehabilitative therapeutic exercises ${ }^{4)}$. Yoga's unique positions are reported to increase activities of the parasympathetic system, which in turn increase the levels of thalamic GABA. In addition,

*Corresponding author. Byoung-Hee Lee (E-mail: 3679@syu. ac.kr)

(C2014 The Society of Physical Therapy Science. Published by IPEC Inc. This is an open-access article distributed under the terms of the Creative Commons Attribution Non-Commercial No Derivatives (by-ncnd) License $<$ http://creativecommons.org/licenses/by-nc-nd/3.0/>. yoga increases the level of peripheral nerve activity ${ }^{5)}$. As the science has developed, virtual reality programs developed for use as games have been applied in many fields. Rehabilitation is one of the fields that uses these types of program for therapeutic purposes. The Wii Fit yoga program from Nintendo, which requires completion of yoga activity in a virtual reality environment, is known to be effective for actually following the yoga movement without any prior professional yoga instructions and training. Therefore, the goal of this research is to explore the therapeutic effects of the Wii Fit program on middle-aged LBP patients through a yoga exercise program.

\section{SUBJECTS AND METHODS}

This research was conducted at a $\mathrm{K}$ hospital located in Seoul with 30 middle-aged female patients who suffer from chronic LBP. Participants were randomly separated into two groups. All participants underwent a thorough examination and were diagnosed as having chronic LBP by a medical doctor with X-ray, CT, and MRI examinations. All of them had been experiencing chronic LBP for longer than two months, and anyone with lowered muscle strength or sensory or cauda equine syndrome was excluded. In the experimental group, a 30-minute virtual reality-based yoga program using Wii Fit activities such as deep breathing, the half-moon pose, warrior pose, tree pose, chest to knee pose, chair pose, and palm tree pose. The virtual reality-based 
yoga programs were performed in a total of 12 sessions over the course of four weeks, with each session lasting 30 minutes.

The general characteristics of the subjects in the experimental group were as follows: a mean age of 44.33 years, a mean height of $158.33 \mathrm{~cm}$, a mean weight of $58.15 \mathrm{~kg}$, a mean body mass index of 22.49 , and a mean mass of muscle of 20.53. Those of the subjects in the control group were as follows: a mean age of 50.46 years, a mean height of $156.55 \mathrm{~cm}$, a mean weight of $56.18 \mathrm{~kg}$, a mean body mass index of 25.06, and a mean mass of muscle of 21.58. There were no significant differences between the groups. The present study was approved by the Sahmyook University Institutional Review Board (SYUIRB2013-036). All participants were given an explanation of the objective of the study and its requirements, and all those who participated provided written informed consent

Participants could readily check their posture and weight bearing on a screen as they shifted their weight or changed their postures on the balance board. There were seven exercise programs. Three minutes of exercise were performed followed by one minute of rest. A longer resting period was provided if desired. Thirty minutes of trunk stabilizing exercise and 30 minutes of normal physical therapy were performed in the control group. Trunk stabilizing exercise was performed with contraction exercise for the transverse abdominis and multifidus followed by curl ups in order to contract the rectus abdominis. The dead bug exercise, quadruped opposite arm and leg reach exercises, bridge, side bridge on knees, middle anterior plank position, and balancing on unstable surfaces were performed. Each movement was comprised of two sets lasting 30 minutes. One set included 10 repetitions.

The visual analog scale (VAS) was used for assessment of pain before and after the intervention. Measurement was performed with a $10-\mathrm{cm}$ scale marked with $1-\mathrm{cm}$ increments. Pain felt by participants was recorded. Pain was rated on a scale of 0 to 10 , with 10 representing the most excruciating pain. The value indicated on the scale by the participant was used as the score. Previous studies have shown that the reliability of the VAS $(\mathrm{r}=0.76-0.84)$ is high ${ }^{7,8}$.

Pressure algometry has proven to be an important psychophysical examination tool for obtaining measures of mechanical pain sensitivity from deep tissue ${ }^{9)}$. It has been widely used in adults, both in experimental and clinical pain conditions ${ }^{10)}$. For example, in osteoarthritis, fibromyalgia, temporomandibular disorders, and whiplash syndrome, reduced pressure pain thresholds in response to mechanical pressure have been shown, indicating the presence of hyperexcitability ${ }^{11)}$. The intra-rater $(\mathrm{r}=0.85)$ and inter-rater $(\mathrm{r}=0.85)$ reliabilities of pressure algometry are high $\left.{ }^{12}\right)$.

The Oswestry low-back pain disability index (ODI) was completed by the participants and included 10 questions assessing activities of daily living in order to examine the functional level when experiencing LBP. Each category was scored from zero to five with regard to the severity of disability caused during daily life ${ }^{13,14)}$. The intraclass correlation coefficient was $r=0.938$, and the Cronbach's alpha was 0.918 (day 1) and 0.895 (day 7) in the validation ${ }^{15,16 \text { ) }}$.
The Roland Morris disability questionnaire (RDQ) was used for measurement of the severity of disability in participants who had less severe LBP. There are 24 categories comprised of yes or no questions. Each participant can have a maximum score of 24 . Scoring closer to 24 indicates greater functional disability ${ }^{17,18)}$. Quoted test-retest correlations include 0.91 (same day), 0.88 (1 week), and 0.83 (3 weeks) $)^{17)}$.

The fear avoidance beliefs questionnaire (FABQ) was used to measure the fear of lower back pain. There are five categories for the FABQ-PA (physical activity) and 11 categories for the FABQ-w (work) with internal consistency $(\alpha)$ of 0.88 and $0.77^{19,20)}$.

SPSS version 17.0 (SPSS Inc., Chicago, IL, USA) was used for statistical analysis. A paired t-test was used to determine the changes in pre- and post-test scores within a group, and the interaction effect between group and time was assessed by using repeated-measures analysis of covariance (ANCOVA) with the baseline as the covariate. An alpha level of $\mathrm{p}<0.05$ was considered significant.

\section{RESULTS}

The results showed that repeated-measures analysis of covariance revealed significant differences between preand post-training VAS, algometer, ODI, RMDQ, and FBQ scores. The VAS, algometer, ODI, and FBQ scores showed significant differences in groups. Regarding the effect of time-by-group interaction, there were significant differences in the VAS, ODI, RMDQ, and FBQ scores (Table 1).

The experimental group showed a significant increase in VAS (from $7.00 \pm 0.89$ points to $2.27 \pm 1.10$ points), algometer (from $7.13 \pm 1.02$ degrees to $4.10 \pm 0.90$ degrees), ODI (from $34.91 \pm 6.19$ points to $13.82 \pm 7.65$ points), RMDQ (from $18.64 \pm 2.84$ points to $7.46 \pm 4.84$ points), and FBQ scores (from $65.46 \pm 9.64$ points to $17.55 \pm 10.67$ points). The control group showed a significant increase in VAS (from $6.95 \pm 0.79$ points to $4.63 \pm 1.91$ points), algometer (from $7.33 \pm 0.87$ degrees to $5.46 \pm 1.57$ degrees), ODI (from $36.18 \pm 5.02$ points to $24.55 \pm 10.88$ points), RMDQ (from $19.09 \pm 2.91$ points to $12.64 \pm 6.48$ points), and FBQ scores (from $70.82 \pm 4.58$ points to $41.64 \pm 18.00$ points).

\section{DISCUSSION}

This research was initiated in order to determine the effects of a virtual reality exercise program using Wii Fit on body function of middle-aged women. There are many causes of LBP. Among them, the main causes are soft tissue injury of the trunk or muscle weakness, which result in lowered endurance, flexibility, and range of motion of the lumbar spine ${ }^{21)}$. Compared with normal people, people who have LBP tend to have weaker and slower-reacting deep spinal muscles, and patients with chronic LBP have increased muscle tension of the lumbar region in the thoracic, inguinal, and femoral muscles ${ }^{22}$.

In order to have normal muscle strength, the muscles, tendons, capsule, and ligaments connected to joints need to have normal extensibility. Yoga, unlike other exercise without sudden contractions of muscles, promotes strengthen- 
Table 1. Comparison of body function between the groups $(\mathrm{n}=30)$

\begin{tabular}{|c|c|c|c|c|c|c|c|}
\hline & \multicolumn{2}{|c|}{ Experimental group $(\mathrm{n}=15)$} & \multicolumn{2}{|c|}{ Control group $(n=15)$} & \multirow{2}{*}{ Group (F) } & \multirow{2}{*}{ Time (F) } & \multirow{2}{*}{$\begin{array}{l}\text { Group } x \\
\text { time }(F)\end{array}$} \\
\hline & Pre & Post & Pre & Post & & & \\
\hline VAS (points) & $7.00 \pm 0.89)^{\mathrm{a}}$ & $2.27(1.10)^{*}$ & $6.95(0.79)$ & $4.63(1.91)^{*}$ & $6.988^{\dagger}$ & $132.151 *$ & $15.451^{*}$ \\
\hline Algometer $\left(\mathrm{kg} / \mathrm{cm}^{2}\right)$ & $7.13(1.02)$ & $4.10(0.90)^{*}$ & $7.33(0.87)$ & $5.46(1.57)^{*}$ & $5.175^{\dagger}$ & $52.534 *$ & 2.974 \\
\hline ODI (points) & $34.91(6.19)$ & $13.82(7.65)^{*}$ & $36.18(5.02)$ & $24.55(10.88)^{*}$ & $4.510^{\dagger}$ & $90.807^{*}$ & $7.578^{\dagger}$ \\
\hline RMDQ (points) & $18.64(2.84)$ & $7.46(4.84)^{*}$ & $19.09(2.91)$ & $12.64(6.48)^{*}$ & 3.057 & 68.654 & $4.933^{\dagger}$ \\
\hline FBQ (points) & $65.46(9.64)$ & $17.55(10.67)^{*}$ & $70.82(4.58)$ & $41.64(18.00)^{*}$ & $13.413^{\sharp}$ & 166.915 & $9.850 *$ \\
\hline
\end{tabular}

VAS, visual analog scale; ODI, Oswestry low-back pain disability index; RMDQ, Roland-morris disability questionnaire; FBQ, Fear avoidance beliefs questionnaire. ${ }^{a} \mathrm{M}(\mathrm{SD}) .{ }^{*} \mathrm{p}<0.01$ from pretest within the group; $\uparrow \mathrm{p}<0.05$ between the two groups; ${ }^{*} \mathrm{p}<0.01$ between the two groups

ing and relaxing of muscles and ligaments. With yoga, right alignment of the body can be sustained. It can aid alleviation of pain through activation of weakened muscles. In addition, adequate relaxation of muscles allows for effective muscle contraction. Thus, yoga can be suggested as a strengthening exercise for weakened muscles. The isometric poses of the Wii Fit yoga programs trains the smaller muscles around the spinal joints to bear more pressure and make the person performing the poses work harder to stabilize themselves. Poses that force us to balance on one leg while standing and change elevation or rotate train supporting muscles to work in ways strictly for stability and balance. Use of a virtual reality system using a computerized environment in which people can experience a similar situation can be helpful in obtaining interactive simulation ${ }^{23}$. Especially in rehabilitation therapy, where repetitive feedback and motor learning are necessary, a virtual reality system can provide adequate motivation of such a mechanism ${ }^{24}$. By providing direct feedback, the virtual reality system created with Wii Fit not only provides fun for participants but also promotes greater balance. This research shows that repeated-measures analysis of covariance revealed significant differences in VAS, algometer, ODI, and FBQ scores in groups. Pain was alleviated, as shown by the VAS, ODI, and FBQ scores in the experimental group compared with the control group.

This result validates that LBP can be eased through use of a virtual reality-based yoga exercise program. In addition, a virtual reality-based yoga program can improve functional level and reduce the fear of low back movement. A study conducted by Carpenter reported that in patients with chronic LBP, a decrease in physical activity would lead to a decrease in lumber muscle size and power, thus causing a repeated increase in LBP and stress, eventually resulting in a vicious circle. For this reason, Carpenter's study suggested that strengthening major weakened muscles such as the lumbar extension muscles could be a method for prevention of such repeating cycles ${ }^{25}$. The virtual reality-based yoga program implemented in this research study encourages postures such as deep breathing, the halfmoon posture, and the tree posture, as with real life yoga, and thus would have induced extension muscle activities. In addition, feedback provided from the virtual reality program would have increased the participant's motivation and concentration. These may have led to the significant result presented in this research.
Because the incidence of LBP in the middle-aged women is higher than that of office workers or laborers, LBP prevention programs and therapeutic interventions are needed. Considering that most middle-aged women do not have time or money for personal health care because of their housekeeping or child-rearing activities, a relatively lowpriced virtual reality-based yoga program would be a more effective and cheaper way to exercise than attending a yoga class at a fitness center.

\section{REFERENCES}

1) Frymoyer JW, Pope MH, Clements JH, et al.: Risk factors in low-back pain. An epidemiological survey. J Bone Joint Surg Am, 1983, 65: 213-218. [Medline]

2) Kovacs FM, Abraira V, Zamora J, et al. Kovacs-Atención Primaria Group: correlation between pain, disability, and quality of life in patients with common low back pain. Spine, 2004, 29: 206-210. [Medline] [CrossRef]

3) Heuch I, Hagen K, Heuch I, et al.: The impact of body mass index on the prevalence of low back pain: the HUNT study. Spine, 2010, 35: 764-768. [Medline]

4) Groessl EJ, Weingart KR, Johnson N, et al.: The benefits of yoga for women veterans with chronic low back pain. J Altern Complement Med, 2012, 18: 832-838. [Medline] [CrossRef]

5) Sakuma Y, Sasaki-Otomaru A, Ishida S, et al.: Effect of a home-based simple yoga program in child-care workers: a randomized controlled trial. J Altern Complement Med, 2012, 18: 769-776. [Medline] [CrossRef]

6) Woitzek K: [Regular yoga improves back function but not pain in patients with chronic back pain]. Prax Bern 1994, 2012, 101: 269-270. [Medline]

7) Mannion AF, Balagué F, Pellisé F, et al.: Pain measurement in patients with low back pain. Nat Clin Pract Rheumatol, 2007, 3: 610-618. [Medline] [CrossRef]

8) Boonstra MC, De Waal Malefijt MC, Verdonschot N: How to quantify knee function after total knee arthroplasty? Knee, 2008, 15: 390-395. [Medline] [CrossRef]

9) Kosek E, Ekholm J, Nordemar R: A comparison of pressure pain thresholds in different tissues and body regions. Long-term reliability of pressure algometry in healthy volunteers. Scand J Rehabil Med, 1993, 25: 117-124. [Medline]

10) Rolke R, Baron R, Maier C, et al.: Quantitative sensory testing in the German Research Network on Neuropathic Pain (DFNS): standardized protocol and reference values. Pain, 2006, 123: 231-243. [Medline] [CrossRef]

11) Arendt-Nielsen L, Nie H, Laursen MB, et al.: Sensitization in patients with painful knee osteoarthritis. Pain, 2010, 149: 573-581. [Medline] [CrossRef]

12) Tunks E, Crook J, Norman G, et al.: Tender points in fibromyalgia. Pain, 1988, 34: 11-19.

13) Fairbank JC, Couper J, Davies JB, et al.: The Oswestry low back pain disability questionnaire. Physiotherapy, 1980, 66: 271-273. [Medline]

14) Kim DY, Lee SH, Lee HY, et al.: Validation of the Korean version of the oswestry disability index. Spine, 2005, 30: E123-E127. [Medline] [CrossRef]

15) Yakut E, Düger T, Oksüz C, et al.: Validation of the Turkish version of the Oswestry Disability Index for patients with low back pain. Spine, 2004. 29: 581-585, discussion 585. [Medline] [CrossRef] 
16) Mousavi SJ, Parnianpour M, Mehdian H, et al.: The Oswestry Disability Index, the Roland-Morris Disability Questionnaire, and the Quebec Back Pain Disability Scale: translation and validation studies of the Iranian versions. Spine, 2006, 31: E454-E459. [Medline] [CrossRef]

17) Roland M, Fairbank J: The Roland-Morris Disability Questionnaire and the Oswestry Disability Questionnaire. Spine, 2000, 25: 3115-3124. [Medline] [CrossRef]

18) Kim KE, Lim JY: Cross-cultural adaptation and validation of the Korean version of the Roland-Morris Disability Questionnaire for use in low back pain. J Back Musculoskeletal Rehabil, 2011, 24: 83-88. [Medline]

19) Waddell G, Newton M, Henderson I, et al.: A Fear-Avoidance Beliefs Questionnaire (FABQ) and the role of fear-avoidance beliefs in chronic low back pain and disability. Pain, 1993, 52: 157-168. [Medline] [CrossRef]

20) Grotle M, Garratt AM, Krogstad Jenssen H, et al.: Reliability and construct validity of self-report questionnaires for patients with pelvic girdle pain. Phys Ther, 2012, 92: 111-123. [Medline] [CrossRef]
21) Koumantakis GA, Watson PJ, Oldham JA: Trunk muscle stabilization training plus general exercise versus general exercise only: randomized controlled trial of patients with recurrent low back pain. Phys Ther, 2005, 85: 209-225. [Medline]

22) Dangaria TR, Naesh O: Changes in cross-sectional area of psoas major muscle in unilateral sciatica caused by disc herniation. Spine, 1998, 23: 928-931. [Medline] [CrossRef]

23) Parsons TD, Bowerly T, Buckwalter JG, et al.: A controlled clinical comparison of attention performance in children with ADHD in a virtual reality classroom compared to standard neuropsychological methods. Child Neuropsychol, 2007, 13: 363-381. [Medline] [CrossRef]

24) Koritnik T, Bajd T, Munih M: Virtual environment for lower-extremities training. Gait Posture, 2008, 27: 323-330. [Medline] [CrossRef]

25) Carpenter DM, Nelson BW: Low back strengthening for the prevention and treatment of low back pain. Med Sci Sports Exerc, 1999, 31: 18-24. [Medline] [CrossRef] 